\title{
Dynamic Hedging in Markov Regimes Switching ${ }^{1}$
}

\author{
Wagner Oliveira Monteiro \\ FGV/EESP \\ wagnerom@hotmail.com \\ Rodrigo De Losso da Silveira Bueno \\ FGV/EAESP \\ rodrigo.bueno@fgv.br
}

\begin{abstract}
This article proposes a bivariate markov switching dynamic conditional correlation model for estimating the optimal hedge ratio between spot and futures contracts. It considers the cointegration between series and allows to capture the leverage effect in return equation. The model is applied using daily data of future and spot prices of Bovespa Index and R $\$ / \mathrm{US} \$$ exchange rate. The results in terms of variance reduction and utility show that the bivariate markov switching model outperforms the strategies based ordinary least squares and error correction models.

Key-words: Dynamic Conditional Correlation, Hedge, Markov Regime Switching.
\end{abstract}

\section{Introduction}

Agents participants of future markets need to buy a optimal number of futures contracts to minimize the variance of their portfolios returns. The prime articles about this subject were Johnson (1960) and Stein (1961). But only in Ederington (1979) and Figlewski (1984) one can find the first derivation of the optimal hedge that equals the ratio of covariance between the spot price variation $\left(S_{t}\right)$ and the future price variation $\left(F_{t}\right)$ by the variance of the future price. Since these works, many studies estimated the optimal hedge ratio using different econometric techniques

Different kinds of estimation methods are used: ordinary least squares [Junkus and Lee (1985)], cointegration [Lien e Luo (1993), Ghosh (1993), Wahab e Lashgari (1993)] and multivariate generalized autoregressive conditional heteroscedasticity models as Kroner and Sultan (1993), Park and Switzer (1995), Gagnon and Lypny (1995, 1997), Brooks, Henry and Persand (2002) and Bystrom (2003). Other possible models are fractional and threshold cointegration as in Lien and Tse (1999), random coefficient as in Bera, Garcia and Roh (1997) and stochastic volatility as in Lien and Wilson (2000).

Theses models can not capture all the most important stylized facts found in financial series. The ordinary least square does not consider the heterocedasticity and the cointegrated relationship between spot and future prices. The error correction model permits to capture the long run relationship between both series and can have a structure for heteroscedastic errors but this kind of model has not been used to estimate the optimal hedge ratio

\footnotetext{
${ }^{1}$ The first author would like to thank the financial support give by FAPESP
} 
yet. Multivariate generalized autoregressive conditional heteroscedasticity models as BabaEngle-Kraft-Kroner, here after, BEKK [Engle and Kroner (1995)] and Dynamic Conditional Correlation (DCC) [Engle (2002)] consider the heteroscedastic behaviour of errors but they have mispecification problems because they do not consider the cointegrated relationship. Another problem with theses models is the structurals breaks that can be present in financial series. These kind of fact can create an estimation where the conclusion is that there are high persistence in the series but there are not.

The aim of this work is to evaluate if a model with a bivariate markov switching regime with two states in the conditional correlation equation of the series can improve the estimation of optimal hedge. For this task we use a bivariate markov switching regime dynamic correlation as in Pelletier (2006) to estimate the optimal hedge for Ibovespa Index and $\mathrm{R} \$ / \mathrm{US} \$$ exchange rate. This model was previously used only by Billio and Caporin (2005) in a contagion analysis. In our model we permit the presence of an error correction term and asymmetry in variance equation The difference between the future price and spot price called basis is used as error correction term. According to Fama and French (1987) the basis has a predictive power for the spot returns.

There are some articles that had applied markov switching regime models to calculate the optimal hedge ratio. Alizadeh and Nomikos (2004).using an ordinary least squares estimation with markov regime switching. Lee and Yoder (2007) proposed a bivariate markov regime switching BEKK model Lee, Yoder, Mittelhammer and McCluskey (2006) used an autoregressive random coefficient markov switching regime model. Finally, Lee and Yoder (2007) calculate the optimal hedging with a time varying correlation garch regime switching model. The model proposed in my work is similar to the Lee and Yoder (2007) article but the structure considers the cointegrated relationship between data, the leverage effect for univariate variance and permits the unconditional correlation to change in the states.

The model is compared with other optimal hedge ratio estimation from ordinary least squares and vector error correction model using the criteria of reduction variance and maximun utility. The results indicate that the model proposed outperforms the other models in-sample.

The text is divided as follow: in section two the model is presented and I explain the measured hedging performance, in section three I discuss the data characteristics and afterwards I present the results of estimation. Then I conclude and make some comments.

\section{A Bivariate Markov Switching Dynamic Conditional Correlation}

In this section I present the model to estimate the optimal hedge ratio. My intention is to elaborate a model that can capture the stylized facts of the series. Since Mandelbrot (1956) we know that financial series usually present facts as clustering, conditional heteroscedastic and assimetry. If a model is not able to capture them, then there will be a mispecification problem. In the case of spot and futures prices the series have a cointegration relationship as shown by Lien and Luo (1993), Kroner and Sultan (1993), Park and Switzer (1995), Lien (1996), Chow (1998) Sarno and Valente (2000), Brooks, Henry and Persand (2002), Yang and Allen (2004), Mili and Abid (2004), Sarno and Valente (2005). In those circustances it is necessary to build a model to embody these characteristics if we want to avoid the 
mispecificaation problem The model presented can capture them all.

\section{$2.1 \quad$ Model}

The model is a bivariate markov switching regime dynamic conditional correlation. First of all, let $s_{t}$ and $f_{t}$ be the $\log$ of the spot and future prices respectively, $S_{t}$ and $F_{t}$, and $\Delta$ be the difference operator, that is $\Delta x_{t}=x_{t}-x_{t-1}$. So $\Delta s_{t}$ represents the spot price variation where the spot price in $t-1$ is subtracted from the spot price in $t$ and $\Delta f_{t}$ represent the future variation where the future price in $t-1$ is subtracted from the future price in $t$.

$$
\begin{gathered}
\Delta s_{t}=c_{s}+\delta_{s}\left(f_{t-1}-s_{t-1}\right)+\varepsilon_{s, t} \\
\Delta f_{t}=c_{f}+\delta_{f}\left(f_{t-1}-s_{t-1}\right)+\varepsilon_{f, t} \\
\epsilon_{t}=\left(\begin{array}{l}
\varepsilon_{s, t} \\
\varepsilon_{f, t}
\end{array}\right) \sim i . i . d\left(0, H_{t}\right)
\end{gathered}
$$

Equations 1 and 2 represente the return build on a constant given by $c_{s}$ and $c_{f}$, an error correction term represented by the difference between future and spot prices in the last period, also know as, the basis of Fama and French (1987) and an error term that has zero average and a variance-covariance matrix given by $H_{t}$ as in equation 4 .

$$
\begin{gathered}
H_{t}=D_{t} R_{t} D_{t} \\
D_{t}=\operatorname{diag}\left(\sigma_{s, t}, \sigma_{f, t}\right) \\
\sigma_{s, t}^{2}=\varpi+\phi_{s} \sigma_{s, t-1}^{2}+\varphi_{s} \varepsilon_{s, t-1}^{2}+\delta_{s} \varepsilon_{s, t-1}^{2} I\left(\varepsilon_{s, t-1}<0\right) \\
\sigma_{f, t}^{2}=\varpi+\phi_{f} \sigma_{f, t-1}^{2}+\varphi_{f} \varepsilon_{f, t-1}^{2}+\delta_{f} \varepsilon_{f, t-1}^{2} I\left(\varepsilon_{f, t-1}<0\right)
\end{gathered}
$$

Where $I\left(\varepsilon_{t}\right)$ is an indicator function that assumes the value 1 for negative values of $\varepsilon_{t-1}$ and 0 otherwise. The equations 6 and 7 are the univariate variance of each series, their structures are given by the last variance and the square of last error observed plus the last term used to verify if there is a difference between the variance caused by negative and positive impacts. This part of model follows Glosten, Jagannathan and Runkle (1993) here after GJR.

$$
\begin{gathered}
R_{t}^{i j}=\left(\tilde{Q}_{t}^{i j}\right)^{-1} Q_{t}^{i j}\left(\tilde{Q}_{t}^{i j}\right)^{-1}, \text { where } \\
Q_{t}^{i j}=\left[1-\alpha_{j}-\beta_{j}-\gamma_{j}\right] \bar{Q}_{j}+\alpha_{j} \eta_{t-1} \eta_{t-1}^{\prime}+\beta_{j} Q_{t-1}^{i} \quad i, j=1 \ldots 2 \text { and } \eta_{t-1}=D_{t}^{-1} \epsilon_{t} \\
\tilde{Q}_{t}^{i j}=\operatorname{diag}\left(\sqrt{q_{11, t}^{i j}}, \sqrt{q_{22, t}^{i j}}\right)
\end{gathered}
$$

The evolution of $H_{t}$ is given by a dynamic correlation model. In this case $H_{t}$ equals $D_{t} R_{t} D_{t}$ as in equation 4 where $D_{t}$ represents a diagonal matrix with the standard deviation of each series as in equation 5 and $R_{t}$ is the correlation matrix that depends on an equation of correlation given by $Q_{t}$ as in equation 9 . This model has the same structure of Engle's (2002) DCC model for conditional correlation where the correlations is given by a constant term, the standardized matrix of residuals and the variance-covariance observed in last period. To avoid problems caused by structural breaks as the persistence in the results I use a 
model that permits the possibility of two different states in economy for dynamic conditional correlation. This structure is identified by upperscript $j$ and $i$ in equations 8,9 and 10, where the upperscript $j$ and $i$ refers to the state in $t, t-1$, respectively. Note that in equation 9 the unconditional correlation has the subscript $j$ indicating that the model permits that its value change in each state.

$$
\operatorname{Pr}\left(s_{t}=1\right)=\frac{1-P_{22, t}}{2-P_{11, t}-P_{22, t}} \text { and } \operatorname{Pr}\left(s_{t}=2\right)=\frac{1-P_{11, t}}{2-P_{22, t}-P_{11, t}}
$$

The ergodic probabilities are given by equations in 11 and indicates the unconditional probabilities of each state. The parameters $P_{11}$ and $P_{22}$ are the probabilities of the transition matrix. For details about the asymptotic properties of model DCC see Engle(2002) and Engle and Sheppard (2002) and for the possibility of a markov switching regime dynamic conditional correlation consult Pelletier (2006).

\subsection{Estimation}

The process the estimation of the model is relatively simple. This kind of model is estimate using a two-step Quasi Maximum Likelihood method following Engle (2002) and a modified Hamilton filter as in Kim(1994). Supose that the full log-lilkelihood can be represented by

$$
\log L(Y)=\frac{1}{T} \sum_{t=1}^{T} \log L\left(Y_{t}\right)=\frac{1}{T} \sum_{t=1}^{T}\left[-\frac{1}{2}\left(\log \left|H_{t}\right|+\varepsilon_{t}^{\prime} H_{t}^{-1} \varepsilon_{t}\right)\right]
$$

but we know from equation 4 that $H_{t}=D_{t} R_{t} D_{t}$ and is possible to prove that $D_{t} R_{t} D_{t}=$ $\left|D_{t}\right|\left|R_{t}\right|\left|D_{t}\right|$, then we conclued that

$$
\log L(Y)=-\frac{1}{2 T} \sum_{t=1}^{T}\left[2 \log \left|D_{t}\right|+\log \left|R_{t}\right|+\varepsilon_{t}^{\prime} D_{t}^{-1} R_{t}^{-1} D_{t}^{-1} \varepsilon_{t}\right]
$$

and replacing $\varepsilon_{t}^{\prime} D_{t}^{-1}$ for $\eta_{t}$ we have that

$$
\log L(Y \mid D)=-\frac{1}{2 T} \sum_{t=1}^{T}\left[2 \log \left|D_{t}\right|+\log \left|R_{t}\right|+\eta_{t} R_{t}^{-1} \eta_{t}\right]
$$

So it is possible to break the estimate of the model into two stages. In the first step I estimate the univariate variance of the each series. With the results from this first estimation, it is possible to estimate the correlation structure of the series. In the case of regime switching, Pelletier (2006) demonstrated the possibility of using a modified Hamilton filter according to Kim (1994), because the value of correlation given by $Q_{t}$ is not observed, as follow:

1. given the filtered probabilities as inputs, determine the joint probabilities:

$$
\operatorname{Pr}\left(s_{t}=j, s_{t-1}=i \mid I^{t-1}\right)=\operatorname{Pr}\left(s_{t}=j, s_{t-1}=i\right) \times \operatorname{Pr}\left(s_{t-1}=i \mid I^{t-1}\right) i, j=1 \ldots 2
$$


2. evaluate the regime dependent likelihood:

$$
\begin{gathered}
Q_{t}^{i j}=\left[1-\alpha_{j}-\beta_{j}\right] \bar{Q}_{j}+\alpha_{j} \eta_{t-1} \eta_{t-1}^{\prime}+\beta_{j} Q_{t-1}^{i} \quad i, j=1 \ldots S \\
\tilde{Q}_{t}^{i j}=\operatorname{diag}\left(\sqrt{q_{11, t}^{i j}}, \sqrt{q_{22, t}^{i j}}\right) \\
R_{t}^{i j}=\left(\tilde{Q}_{t}^{i j}\right)^{-1} Q_{t}^{i j}\left(\tilde{Q}_{t}^{i j}\right)^{-1} \\
\log _{t}\left(Y_{t} \mid D_{t}, s_{t}=j, s_{t-1}=i, I^{t-1}\right)=-\frac{1}{2 T}\left(\log \left|R_{t}^{i j}\right|+\eta_{t}^{-1}\left(R_{t}^{i j}\right)^{-1} \eta_{t}\right)
\end{gathered}
$$

3. evaluate the likelihood of observation $t$ :

$$
\begin{aligned}
\log _{t}\left(Y_{t} \mid D_{t}, I^{t-1}\right)= & \sum_{j=1}^{S} \sum_{i=1}^{S} \log L_{t}\left(Y_{t} \mid D_{t}, s_{t}=j, s_{t-1}=i, I^{t-1}\right) \times \\
& \operatorname{Pr}\left(s_{t}=j, s_{t-1}=i \mid I^{t-1}\right) \\
\log L\left(Y_{t}, \ldots, Y_{1}\right)= & \log L\left(Y_{t-1}, \ldots, Y_{1}\right)+\log L_{t}\left(Y_{t} \mid D_{t}, I^{t-1}\right)
\end{aligned}
$$

4. update the joint probabilties:

$$
\operatorname{Pr}\left(s_{t}=j, s_{t-1}=i \mid I^{t-1}\right)=\frac{\log L_{t}\left(Y_{t} \mid D_{t}, s_{t}=j, s_{t-1}=i, I^{t-1}\right) \times \operatorname{Pr}\left(s_{t}=j, s_{t-1}=i \mid I^{t-1}\right)}{\log L_{t}\left(Y_{t} \mid D_{t}, I^{t-1}\right)}
$$

5. compute the filtered probabilities:

$$
\operatorname{Pr}\left(s_{t}=j \mid I^{t}\right)=\sum_{i=1}^{2} \operatorname{Pr}\left(s_{t}=j, s_{t-1}=i \mid I^{t}\right) \quad j=1 \ldots 2
$$

6. update the correlation matrix using the following approximation:

$$
Q_{t}^{j}=\frac{\sum_{i=1}^{2} \operatorname{Pr}\left(s_{t}=j, s_{t-1}=i \mid I^{t}\right) \times Q_{t}^{i j}}{\operatorname{Pr}\left(s_{t}=j \mid I^{t}\right)}
$$

7. iterate 1 to 6 until the end of sample.

The bivariate markov switching regime model will be estimated using GAUSS 6.0 software, applyed the Constrained Optimization code. To compare the proposed model I estimate the ordinary least squares and vector error correction model too. 


\subsection{Optimal Hedge Ratio}

To obtain the variance-covariance matrix for each instant of time, given that I have two different possible states of economy I use the conditional expectation as in Pelletier (2006) given by equation 26 :

$$
E\left[H_{t}\right]=D_{t} E\left[R_{t}\right] D_{t}
$$

where $D_{t}$ is the standard deviations of univariate variance estimation as in equation 5 and $R_{t}$ is the conditional expectational correlation matrix given by equation 8 . To calculate the expected value of $R_{t}$ is used the expression given by equation 27 :

$$
E\left[R_{t}\right]=R_{1, t+1} \times \operatorname{Pr}\left(s_{t}=1 \mid I^{t}\right)+R_{2, t+1} \times \operatorname{Pr}\left(s_{t}=2 \mid I^{t}\right)
$$

So for each point in time there will be two different correlations and, consequently, two differents hedge ratios. I will use an optimal hedge ratio calculated from two distincts correlations weighted by their respectives filtered probabilities given by equations in 11 estimated endogeously in the model.

\section{Measuring Hedging Perfomance}

In this section I present the two different measurements used in this dissertation to evaluate the optimal hedge ratio.

\subsection{Utility}

This measurement supposes that the agent's utility function is quadratic as in equation 28. According to the literature, the parameter $\rho$ assumes values between 1 and 4 . It represents the risk aversion of the agent. This utility function is used by Kroner and Sultan (1993), Gagnon et al. (1998) and Lafuente Novales (2003) to evaluate different kinds of hedge strategies.

$$
E_{t} U\left(r_{t}\right)=E_{t}\left(r_{p, t}\right)-\rho \sigma_{t}^{2}\left(r_{p, t}\right)
$$

Where $r_{p, t}=\Delta s_{t}-\gamma_{t}^{*} \Delta f_{t}$ is the return of the agent's portfolio, the parameter $\gamma$ is the optimal hedge ratio given by each model and $\sigma_{t}^{2}\left(r_{p, t}\right)$ is the variance of portfolio given by $\operatorname{Var}\left(\Delta s_{t}-\gamma_{t}^{*} \Delta f_{t}\right)$. The value of $E_{t}\left(r_{p, t}\right)$ is considered zero as in other articles. So the value of the utility will be negative because the values of $\rho$ and $\sigma_{t}^{2}\left(r_{p, t}\right)$ are positive. The strategy with high utility is the best choice for the agent that are willing to minimize the variance of their portfolio.

\subsection{Variance Reduction}

The purpose of the variance reduction is to compare the portfolio variance reduction using the strategy of the estimated model over the strategy where the agent does not buy any future contract. First of all it is calculated the agent's portfolio variance using 29 .

$$
\operatorname{Var}\left(r_{p, t}\right)=\operatorname{Var}\left(\Delta s_{t}-\gamma_{t}^{*} \Delta f_{t}\right)
$$


The parameter $\gamma$ is the optimal hedge ratio given by each model. Equation 30 shows the variance reduction compared to an unhedge strategy, in other words, a strategy where $\gamma$ is zero .

$$
1-\frac{\operatorname{Var}\left(r_{p, t}\right)_{h}}{\operatorname{Var}\left(r_{p, t}\right)_{u}}
$$

In 30 the subscript $h$ and $u$ refers to hedge and unhedge, respectively. The higher the value of 30 , the better the model is. The model which has the highest value for the statistic outperforms all the other ones.

\section{Data Description}

I used the Bovespa Index spot and future and R $\$ / \mathrm{US} \$$ exchange rate spot and future to estimate the models. The future data sample consists of settlement price from $03 / 01 / 2000$ to $15 / 02 / 2006$. To build the series, it is used the most liquid contract near the due date.

\subsection{Ibovespa}

In figures 1 and 2 we can see the behavior of log level and return for each series. The stylized facts as clustering and variant variance can be verified. And it is possible to see in this sample that the data appear to have a positive trend in log level. As expected, the future and spot series are very similar. So we can expect that conditional correlation be time varying but in a determined level be close to one.

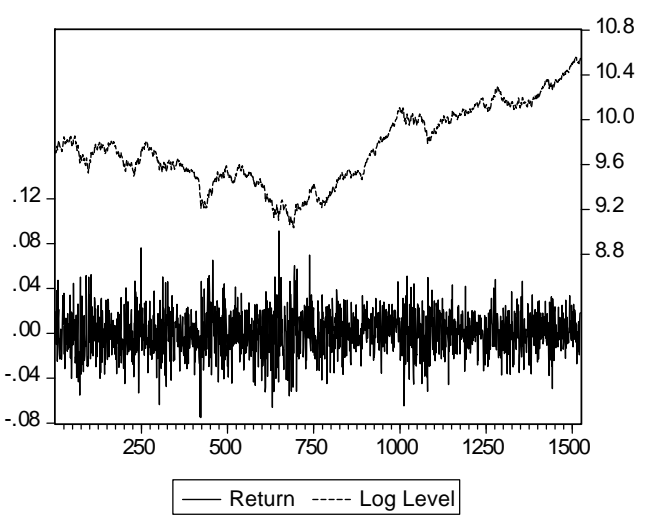

Figure 1: Future Ibovespa. From BMF.

Table 1 has the summary statistics of the series. It is possible to verify that the return of each series has a negative skewness or a negative asymmetry, this fact indicates that using a GJR model for univariate variance is a good choice and that the series has excess kurtosis in first difference or return. The value of kurtosis is very low for a financial data, near 3 . This fact can be explain by a sample characteristic. 


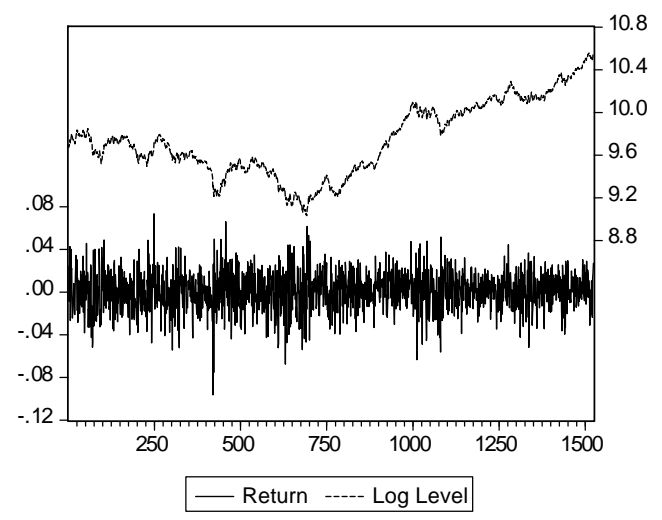

Figure 2: Spot Ibovespa. From BMF.

Table 1 - Summary Statistics

\begin{tabular}{ccccc}
\hline \hline & \multicolumn{2}{c}{ Log Level } & \multicolumn{2}{c}{ Return } \\
\hline \hline & Spot & Futures & Spot & Futures \\
\hline Mean & 9.742229 & 9.752695 & 0.000579 & 0.000555 \\
Median & 9.704321 & 9.718663 & 0.000939 & 0.000984 \\
Maximum & 10.55800 & 10.55579 & 0.073353 & 0.091306 \\
Minimum & 9.032409 & 9.035630 & -0.096342 & -0.074941 \\
Std. Dev. & 0.346388 & 0.344983 & 0.018929 & 0.020011 \\
Skewness & 0.229525 & 0.220043 & -0.243482 & -0.029039 \\
Kurtosis & 2.190144 & 2.190886 & 4.022739 & 3.612698 \\
\hline
\end{tabular}

In table 2 I present the result of Unit Root Test ${ }^{2}$ for future and spot series. All tests say that the serie has a unit root in level and is stationary in the first difference. Only by KPSS test we have that the series have a unit root in first difference in a level of $1 \%$. This fact can occur because in some point of figure 2 and 1 it is possible to see high positive and negative values for return that can cause this kind of problem.

Table 2 - Unit Root Test

\begin{tabular}{ccccc}
\hline \hline & ADF & PP & ERS & KPSS \\
\hline Future Log Level & 0.038 & 0.189 & 17.832 & 2.772 \\
Future Return & -38.925 & -39.009 & 0.059 & 0.390 \\
Spot Log Level & 0.207 & 0.302 & 21.040 & 2.778 \\
Spot Return & -37.923 & -37.929 & 0.082 & 0.407 \\
$1 \%$ & -3.434 & -3.434 & 1.99 & 0.739 \\
$5 \%$ & -2.863 & -2.863 & 3.26 & 0.463 \\
$10 \%$ & -2.567 & -2.567 & 4.48 & 0.347 \\
\hline
\end{tabular}

In table 3 I present the Johansen Cointegration test applied with no trend and an irrestrit constant $^{3}$. The result of the test is that the series are cointegrated in level. This indicate

\footnotetext{
${ }^{2}$ I applied the Augmented Dickey-Fuller (ADF), Phillips-Perron (PP), Kwiatkowski, et. al. (KPSS), Elliot, Richardson and Stock (ERS) Point Optimal test.

${ }^{3}$ But for all possibles combinations I found out at least one cointegration relations
} 
that the model needs to consider this relationship when modelling the joint behavior of the series.

Table 3 - Johansen Cointegration Test

\begin{tabular}{ccccc}
\hline \hline No CE & Trace Statistic & Critical Value & Max-Eingen Statistic & Critical Value \\
\hline None & 140.157 & 15.494 & 140.142 & 14.264 \\
At most one & 0.015 & 3.841 & 0.015 & 3.841 \\
\hline
\end{tabular}

\subsection{Exchange rate}

In figures 3 and $4 \mathrm{I}$ show the behavior of the log level and return of exchange rate data. Again it is possible to see that the stylized facts are present in these series. But different from index data this one does not have a trend. So, it is interesting to use our model in these two different data.

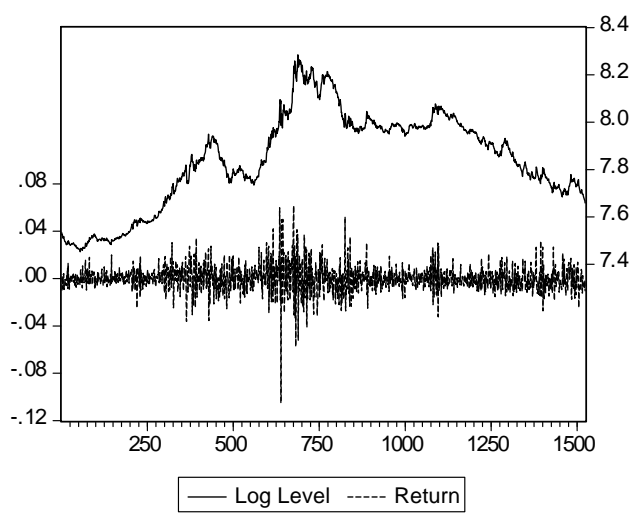

Figure 3: R $\$ / \mathrm{US} \$$ Future. From: BMF.

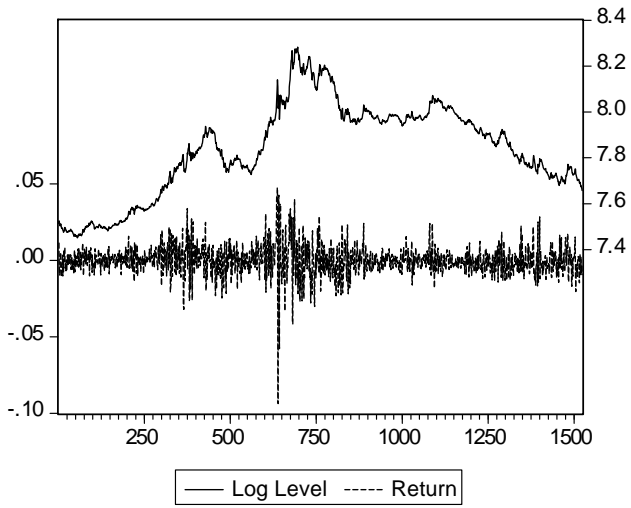

Figure 4: R\$/US\$ Spot. From: BACEN.

In Table 4 I present the summary statistics of the spot and future exchange rate in log level and in return. Again it is possible to say that the series have negative skewness but the 
excess of kurtosis in first difference is much higher for currency data compared with index data. So exchange rate series present the common financial series stylized facts.

Table 4 - Summary Statistics

\begin{tabular}{ccccc}
\hline \hline & \multicolumn{2}{c}{ Log Level } & \multicolumn{2}{c}{ Return } \\
\hline \hline & Spot & Futures & Spot & Futures \\
\hline Mean & 7.837422 & 7.841825 & $9.46 e-05$ & $8.25 e-05$ \\
Median & 7.849246 & 7.856752 & -0.000180 & -0.000346 \\
Maximum & 8.282685 & 8.284450 & 0.047583 & 0.061572 \\
Minimum & 7.451822 & 7.452724 & -0.093604 & -0.105023 \\
Std. Dev. & 0.201346 & 0.200539 & 0.009513 & 0.010949 \\
Skewness & -0.176943 & -0.208389 & -0.509710 & -0.120257 \\
Kurtosis & 2.282702 & 2.257729 & 12.40289 & 11.99867 \\
\hline
\end{tabular}

In Table 5 it is presented the result of Unit Root Test for future and spot exchange rate in log level and first difference. All tests say that the series has a unit root in level and is stationary in the first difference but this is not true for KPSS test in a level of 1\%. Again this fact can occur because in some points of figures 2 and 1 it is possible to see high positive and negative values for return.

Table 5 - Unit Root Test

\begin{tabular}{ccccc}
\hline \hline & ADF & PP & ERS & KPSS \\
\hline Future Log Level & -1.4241 & -1.397 & 36.034 & 1.995 \\
Future Return & -41.689 & -41.677 & 0.057 & 0.562 \\
Spot Log Level & -1.408 & -1.449 & 47.095 & 1.977 \\
Spot Return & -28.651 & -32.243 & 0.074 & 0.598 \\
$1 \%$ & -3.434 & -3.434 & 1.99 & 0.739 \\
$5 \%$ & -2.863 & -2.863 & 3.26 & 0.463 \\
$10 \%$ & -2.567 & -2.567 & 4.48 & 0.347 \\
\hline
\end{tabular}

In Table 6 I present the Johansen Cointegration test applied with a costant and without trend ${ }^{4}$. The result of this test is that the series are cointegrated in level. So it is possible to say again that the model needs to consider this relationship when modelling the joint behavior of series.

Table 6 - Johansen Cointegration Test

\begin{tabular}{ccccc}
\hline \hline No CE & Trace Statistic & Critical Value & Max-Eingen Statistic & Critical Value \\
\hline None & 300.143 & 15.494 & 298.078 & 14.264 \\
At most one & 2.065 & 3.841 & 2.065 & 3.841 \\
\hline
\end{tabular}

\section{$5 \quad$ Estimation Results}

In this section I present the results from the estimated models: ordinary least square, vector error correction model and bivariate markov switching regime model for each data series.

\footnotetext{
${ }^{4}$ But for all possibles combinations I found out at least one cointegration relations
} 


\subsection{Ibovespa}

\subsubsection{Ordinary Least Squares}

In equation $31 \mathrm{I}$ show the result of the Ordinary Least Squares model. It is possible to note that all estimated parameters are significant at 5\%. Using this model I conclude that the optimal hedge is 0.88 . This will be the value used to evaluate the optimal hedge ratio strategy calculated from ordinary least squares model. For this model the $R^{2}$ statistic is 0.89 .

$$
\Delta s_{t}=\underset{(0.0001)}{0.00008}+\underset{(0.008)}{0.885} \times \Delta f_{t}
$$

Only for the good of science or perhaps curiosity I estimate an ordinary least squares model with an extra variable: the basis. The result is shown in equation 32 In this case I can infer that the constant parameter and the new parameter included have statistical significance. So I verified that the value of the basis in $t-1$ has statistical significance to explain the exchange rate spot return in $t$. The $R^{2}$ statistic is of 0.90 .

$$
\Delta s_{t}=\underset{(0.0002)}{0.002}+\underset{(0.007)}{0.90} \times \Delta f_{t}-\underset{(0.015)}{0.206} \times\left(f_{t-1}-s_{t-1}\right)
$$

I use the optimal hedge ratio from 31 because in 32 the parameter of future variable return is not any more equal the ratio between covariance of spot and future return and the variance of future return.

\subsubsection{Error Correction Model}

The Error Correction Model results can be observed in equations 33, 34 and 35. The adjustment parameter is not significant in the equation of spot returns given by equation 33 but it is in the equation of future returns given by equation 34, so I can infer that it is the future price that adjusts the long-run relationship. The spot prices appear not to have an autoregressive component and the value of future price in $t-1$ can not help explaining the value of spot price in $t$ given that these two parameters are not significant. For future prices it happened the opposite, the last value of spot prices and the autorregressive compenent are significant to explain the value of future price in $t$. This fact indicates that future prices adjust itself after a shock to keep the long-run relationship.

$$
\begin{gathered}
\Delta s_{t}=\underset{(0.0004)}{0.0005}+\underset{(0.083)}{0.046} \times \Delta s_{t-1} \underset{(0.078)}{-0.008} \times \Delta f_{t-1}+\underset{(0.055)}{0.046} \times z_{t-1} \\
\Delta f_{t}=\underset{(0.00051)}{0.0005}+\underset{(0.088)}{0.227} \times \Delta s_{t-1} \underset{(0.083)}{0.0 .188} \times \Delta f_{t-1} \underset{(0.058)}{-0.156} \times z_{t-1} \\
\text { where } z_{t-1}=\left(f_{t-1} \underset{(0.002)}{-0.995} \times s_{t-1}-0.058\right)
\end{gathered}
$$

The parameter value in the cointegrated vector given by equation 35 estimated is significant at $5 \%$ and is nearly 1 . A probable indication that the basis can be used as an error correction term. To calculate the optimal hedge ratio for this model it is necessary to calculate the ratio between the covariance of residuals from equations of spot and future returns given by equations 33 and 34 and the variance of residuals from equation of future return given by equation 34. The value that I have found out was 1.0166. 


\subsubsection{Markov Switching Dynamic Conditional Correlation Model}

In equations 36 and $37 \mathrm{I}$ can verify the results for equation return of each index series. The parameter that represents the error correction term is significant only in future return equation, as seen in the results of error correction model.

$$
\begin{gathered}
\Delta s_{t}=\underset{(0.046)}{0.0001}+\underset{(0.046)}{0.040} \times\left(f_{t-1}-s_{t-1}\right) \\
\Delta f_{t}=\underset{(0.0006)}{0.002}-\underset{(0.046)}{0.166} \times\left(f_{t-1}-s_{t-1}\right)
\end{gathered}
$$

The results of the variance equation for each serie are in equations 38 and 39 . We can note that the model captures a leverage effect, or in other words, the model capture of different ways negative impacts ("bad news") and positive impacts in variance equation as in the literature.

$$
\begin{gathered}
\sigma_{s, t}^{2}=\underset{(0.000003)}{0.00001}+\underset{(0.017)}{0.928} \times \sigma_{s, t-1}^{2}-\underset{(0.01)}{0.008 \times \varepsilon_{s, t-1}^{2}}+\underset{(0.016)}{0.087 \times I}\left(\varepsilon_{s, t-1}\right) \times \varepsilon_{s, t-1}^{2} \\
\sigma_{f, t}^{2}=\underset{(0.000002)}{0.000009}+\underset{(0.013)}{0.943} \times \sigma_{f, t-1}^{2}-\underset{(0.009)}{0.011} \times \varepsilon_{f, t-1}^{2}+\underset{(0.016)}{0.085} \times I\left(\varepsilon_{f, t-1}\right) \times \varepsilon_{f, t-1}^{2}
\end{gathered}
$$

In figure 5, I plot the estimate variance for both sample series.
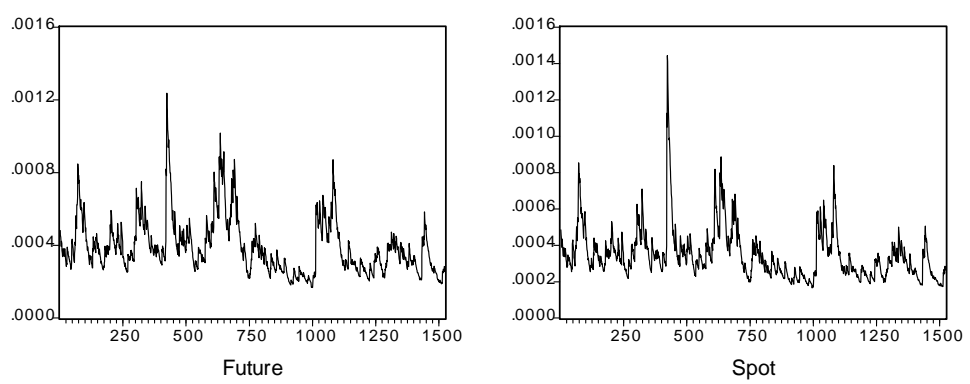

Figure 5: Estimated Variance

In the second stage, I estimate the conditional correlation between series using the residuals from the univariate variance estimations. The results are shown in equations 40 and 41. According to the estimates, there are two different states for series correlation. In state one, the unconditional correlation is equal 0.980 and in state two, the value is 0.605 . I can infer that both estimated parameters are significant at 5\%. So in state one there is a high positive correlation between series and the state two has a low correlation between series. The parameter estimated are not significant and in state one the vale of parameter $\alpha$ is zero.

$$
\begin{gathered}
Q_{t}^{1}=[1-\underset{(0.021)}{0}-\underset{(0.063)}{0.019}] \underset{(0.001)}{\times 0.980}+\underset{(0.021)}{0} \times \eta_{t-1} \eta_{t-1}^{\prime}+\underset{(0.063)}{0.019} \times Q_{t-1}^{1} \\
Q_{t}^{2}=[1-\underset{(0.051)}{0.014}-\underset{(0.468)}{0.331}] \times \underset{(0.051)}{0.605}+\underset{(0.034)}{0} \times \eta_{t-1} \eta_{t-1}^{\prime}+\underset{(0.468)}{0.331} \times Q_{t-1}^{2}
\end{gathered}
$$


In figure 6 is shown the behavior of estimated correlation. I can infer that in state one there is a high correlation and state two the correlation is lower than state one again. In state one the range of correlation is equal 0.007 but in a high level correlation and in state two the correlation range is high but in a lower level compared with state one.
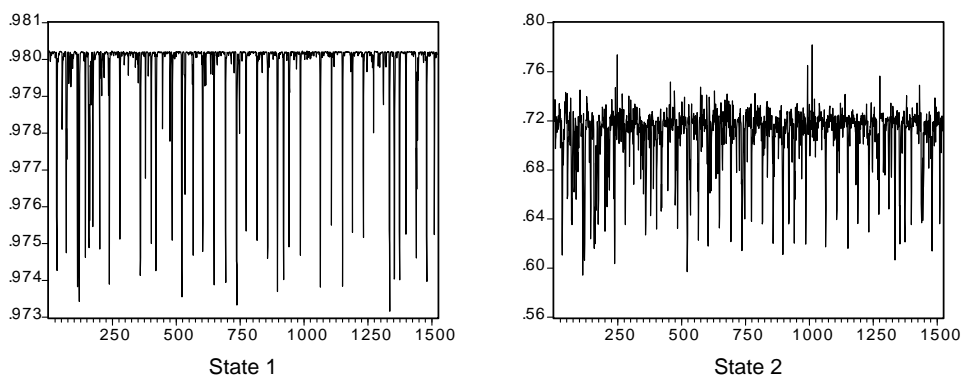

Figure 6: Correlation

In Table 7 are the transitions probabilities of the model. Using this information we can conclude that state one has a duration of $\frac{1}{1-0.9498}=19.92$ days and state two has a duration of $\frac{1}{1-0.4879}=1.9527$ days. The ergodic probabilities are given by $\frac{1-0.4879}{2-0.9498-0.4879}=0.91072$ for state one and $\frac{1-0.9498}{2-0.9498-0.4879}=0.08928$ for state two. So we can conclude that for this sample, the probability of conditional correlation between series is bigger for state one than state two.

\begin{tabular}{c||cc}
\multicolumn{2}{c}{ Table 7 - Probabilities Transition } \\
& State One & State Two \\
\hline \hline State One & 0.9498 & 0.0502 \\
State Two & 0.5121 & 0.4879
\end{tabular}

In figure 7 I show the filtered probabilities of each state. They indicate that in each state the probability of been in state one is bigger than state two for each $t$.
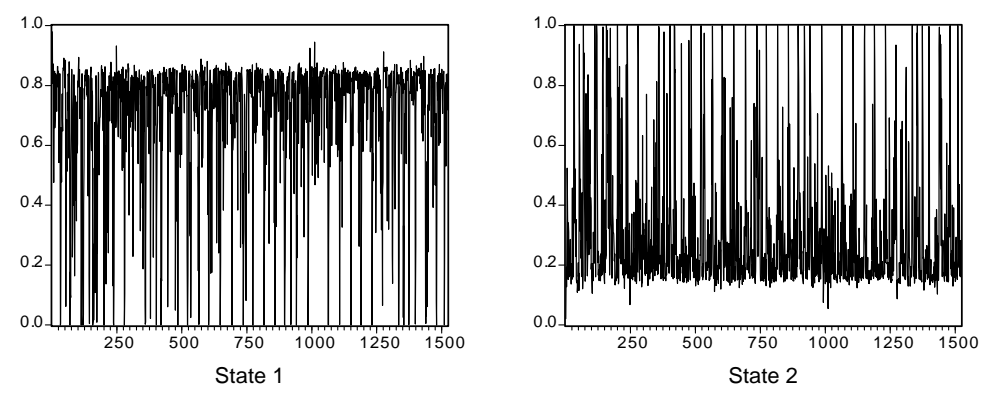

Figure 7: Filtered Probabilities

I plote in figure 8 the optimal hedge ratio estimate in each state. Both series are very similar. In the state one the correlation between spot and future Ibovespa index is close to one so the optimal hedge ratio is close to one too for each $t$. In the state two the value of optimal hedge ratio is less than that of state one because the conditional correlation between 

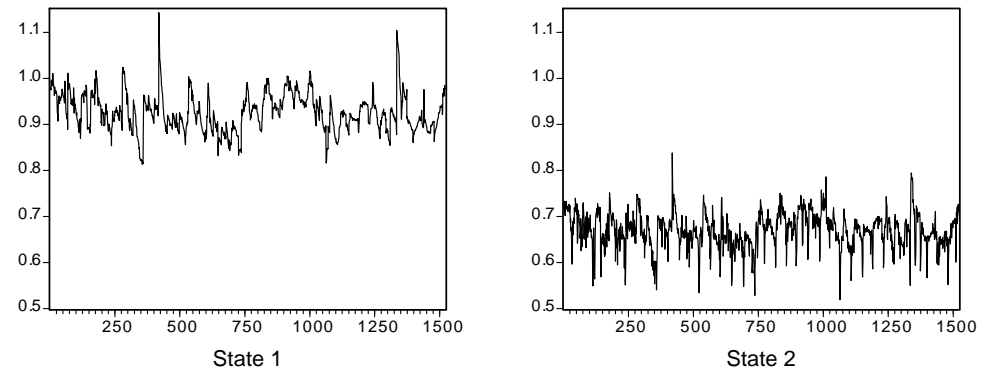

Figure 8: Optimal Hedge Ratio

the series presents this behavior too. Another observation is that both graphs are similar but in differents levels.

In figure 9 are the expected optimal hedge ratio calculated using the hedge ratio in each state and their respectives filtered probabilities. The serie floats between 0.9 and 0.8 . In some points there is a trend to achieve values close of 0.6 .

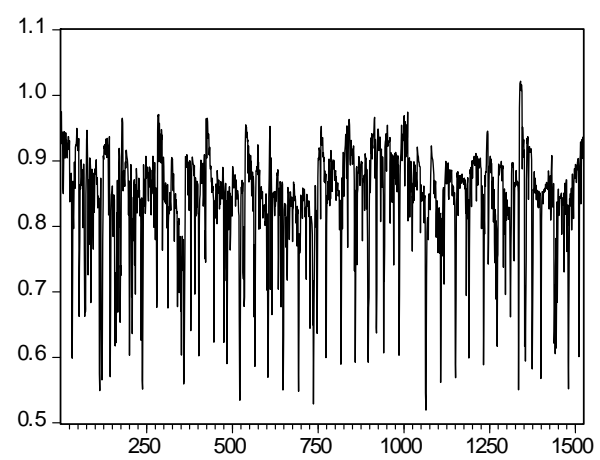

Figure 9: Expected Optimal Hedge Ratio

\subsubsection{Variance Reduction}

In Table 8 are the results of model's evaluation using the variance reduction criterion. Second this judge the best strategy in-the-sample is given by switching regime model reducing the variance in $89.86 \%$ followed by ordinary least squares model that can reduce the variance in $89.44 \%$, the values are very close.

\begin{tabular}{|c|c|c|}
\hline \multicolumn{3}{|c|}{ Table 8 -Variance Reduction } \\
\hline & Variance & Reduction \\
\hline$\overline{\text { Unhedge }}$ & 0.0003510351797 & \\
\hline Naive & 0.0000423391708 & $87.94 \%$ \\
\hline OLS & 0.0000370814818 & $89.44 \%$ \\
\hline ECM & 0.0000435916178 & $87.58 \%$ \\
\hline MSDCC & 0.0000355961241 & $89.86 \%$ \\
\hline
\end{tabular}


The values for variance reduction is very high, almost $90 \%$ so I can conclude that some kind of strategy buying future contracts of Ibovespa index can reduced significantly the variance of agent's portfolio.

\subsubsection{Utility}

In Table 9 are presented the values of utility obtained by equation 28 using the results of each model or strategy. For all value of coefficient risk aversion the switching regime model is the better choice compared with ordinary least squares and vector error correction models. The curios fact is that the naive strategy is a better choice than vector error correction model.

\begin{tabular}{ccccc}
\hline \multicolumn{5}{c}{ Table 9 - Measure Utility } \\
\hline Risk Aversion & $\mathbf{1}$ & $\mathbf{2}$ & $\mathbf{3}$ & $\mathbf{4}$ \\
\hline \hline Unhedge & -0.000351 & -0.000702 & -0.001053 & -0.001404 \\
Naive & -0.000042 & -0.000085 & -0.000127 & -0.000169 \\
OLS & -0.000037 & -0.000074 & -0.000111 & -0.000148 \\
ECM & -0.000044 & -0.000087 & -0.000131 & -0.000174 \\
MSDCC & -0.000036 & -0.000071 & -0.000107 & -0.000142 \\
\hline
\end{tabular}

\subsection{Exchange Rate}

\subsubsection{Ordinary Least Squares}

In equation 42 I can evaluate the result of the ordinary least squares model. It is possible to note that only the parameter of future return is significants at $5 \%$. Using this model I conclude that the optimal hedge is 0.535 for exchange rate, a less value when compared with index optimal hedge ratio from ordinary least squares. This will be the value used to evaluate the optimal hedge ratio calculated from ordinary least squares model. For this model we have a $R^{2}$ statistic of 0.38 . The values of the optimal hedge ratio parameter and $R^{2}$ statistic is less than compared with the values for index results.

$$
\Delta s_{t}=\underset{(0.0001)}{0.00005}+\underset{(0.017)}{0.535} \times \Delta f_{t}
$$

As before I estimate an ordinary least squares model with a one more variable in the model: the basis. The result is presented in equation 43 In this case the constant parameter and the new parameter include have statistician significant. So it is possible to say that the basis in $t-1$ has statistician significant to explain the return of spot exchange rate in $t$. The $R^{2}$ statistic is of 0.63 .

$$
\Delta s_{t}=\underset{(0.0001)}{-0.002}+\underset{(0.013)}{0.583} \times \Delta f_{t}+\underset{(0.019)}{0.634} \times\left(f_{t-1}-s_{t-1}\right)
$$

Note how the value of $R^{2}$ increased with an addiotinal explicative variable when compared with the same situation in index results. I use the optimal hedge ratio from 42 because in 43 the parameter of future return explicative variable in equation 43 is not any more equal 
the ratio between covariance of spot and future return and the variance of future return as in equation 42 .

\subsubsection{Error Correction Model}

For Error Correction Model the results to exchange rate can be observed in equations 44, 45 and 46 . It can be noted that the parameter of adjustment is significant in both equations and assumes a positive value to spot equation and a negative value to future equation. So I can infer that both prices adjust the long-run relationship and that spot exchange rate needs to increase and future exchange rate needs to decrease to do it. The spot prices appear not to have an autoregressive component and the value of return future price in $t-1$ can help predicting the value of spot price in $t$. For future prices, the last value of spot prices and an autoregressive component are significant to explain the value of future price in $t$.

$$
\begin{gathered}
\Delta s_{t}=\underset{(0.0002)}{0.00006}-\underset{(0.031)}{0.001} \times \Delta s_{t-1}+\underset{(0.078)}{0.222} \times \Delta f_{t-1}+\underset{(0.037)}{0.369} \times z_{t-1} \\
\Delta f_{t}=\underset{(0.00028)}{0.0008}+\underset{(0.040)}{0.117} \times \Delta s_{t-1} \underset{(0.042)}{0.093} \times \Delta f_{t-1} \underset{(0.048)}{0.094} \times z_{t-1} \\
\text { where } z_{t-1}=\left(f_{t-1} \underset{(0.001)}{-0.996} \times s_{t-1}-0.033\right)
\end{gathered}
$$

A last comment is about the cointegration vector. The parameter value estimated is significant at $5 \%$ and is nearly 1. A probable indication that the basis can be used as a proxy of an error correction term. To calculate the optimal hedge ratio for this model is necessary to calculate the ratio between the covariance of residuals from equations 44 and 45 and the variance of residuals from equation 45. The value found out were 1.0069. A value higher than that one predicted by the ordinary least squares model.

\subsubsection{Markov Switching Dynamic Correlation Model}

In equations 47 and 48 it is possible to verify the results for equation return of future and spot exchange rate. The parameter value of basis is significant in both equations as in error correction model. It is observed that the signs of the parameter's error correction term is the same that those found out in equations 44 and 45, indicating that to repair the long-run relationship it is necessary that spot exchange rate increase and that future exchange rate decrease. So both data need adjustment to repair the long-run relationship.

$$
\begin{gathered}
\Delta s_{t}=\underset{(0.0001)}{0.002}+\underset{(0.024)}{0.521} \times\left(f_{t-1}-s_{t-1}\right) \\
\Delta f_{t}=\underset{(0.0002)}{0.0008}-\underset{(0.035)}{0.172} \times\left(f_{t-1}-s_{t-1}\right)
\end{gathered}
$$

The results of the univariate variance to spot and future exchange rate are in equations 49 and 50, respectively. Note that the model captures a leverage effect, or in other words, the model captures of different ways negative impacts and positive impacts as in literature for both variance equations. Anotther interesting fact to note is that sign of the leverage 
effect parameter is negative, the opposite of index results indicating that negative impacts reduce the variance.

$$
\begin{gathered}
\sigma_{s, t}^{2}=\underset{(0.000003)}{0.00001}+\underset{(0.018)}{0.808} \times \sigma_{s, t-1}^{2}+\underset{(0.026)}{0.245 \times \varepsilon_{s, t-1}^{2}} \underset{(0.025)}{0.132 \times I} \times\left(\varepsilon_{s, t-1}\right) \times \varepsilon_{s, t-1}^{2} \\
\sigma_{f, t}^{2}=\underset{(0.000003)}{0.00001}+\underset{(0.012)}{0.877} \times \sigma_{f, t-1}^{2}+\underset{(0.015)}{0.137 \times \varepsilon_{f, t-1}^{2}} \underset{(0.015)}{0.044} \times I\left(\varepsilon_{f, t-1}\right) \times \varepsilon_{f, t-1}^{2}
\end{gathered}
$$

In figure $10 \mathrm{I}$ plot the variances estimatives of both series. According to them I can infer that the variance of spot exchange rate and the variance of future exchange rate are very similar and that they are clearly variant in time.
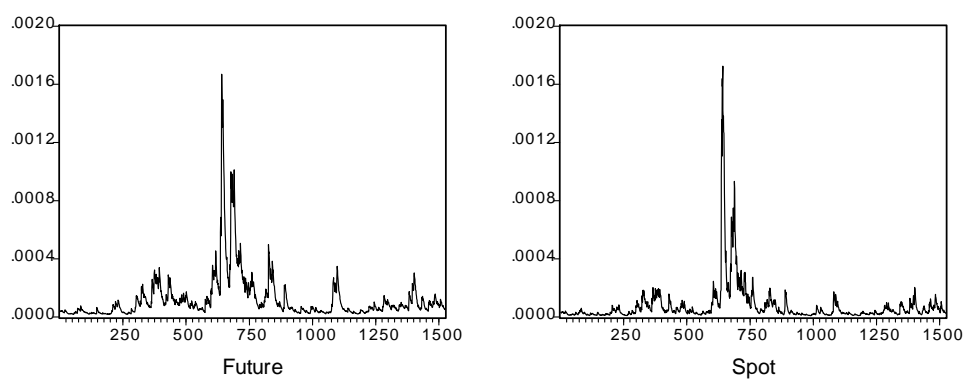

Figure 10: Variance Estimated

In the second stage, I estimate the conditional correlation between series using the residuals from the univariate models. The results are in equations 51 and 52. According to the estimates there are two differents states for correlation between spot and future exchange rate. In state one the unconditional correlation is equal 0.899 and in state two this value is 0.560. The estimatives parameters $\alpha$ and $\beta$ estimated are not significant and in state two, given by equation 52 , the value of parameter $\alpha$ is zero.

$$
\begin{gathered}
Q_{t}^{1}=[1-\underset{(0.029)}{0.005}-\underset{(0.111)}{0.681}] \underset{(0.039)}{0.899}+\underset{(0.029)}{0.005} \times \eta_{t-1} \eta_{t-1}^{\prime}+\underset{(0.111)}{0.681} \times Q_{t-1}^{1} \\
Q_{t}^{2}=[1-\underset{(0.034)}{0}-\underset{(0.214)}{0.597}] \times \underset{(0.075)}{0.560}+\underset{(0.034)}{0} \times \eta_{t-1} \eta_{t-1}^{\prime}+\underset{(0.214)}{0.597} \times Q_{t-1}^{2}
\end{gathered}
$$

In figure 11 I plote the behavior of estimated correlation between series. For state one the estimated correlation between spot and future exchange rate floats around a level of 0.8 and for state two the correlation floats around a level of 0.6 , as expected, a positive and high value, very close to one. This can indicate that both series are almost always very close and in some moments their keep a high correlation but in a lower level.

In table 10 are the transitions probabilities of the model. Using this information I can conclude that in average the state one has a duration of $\frac{1}{1-0.8420}=6.3291$ days and state two has a duration of $\frac{1}{1-0.804}=5.102$ days. The ergodic probabilities are given by $\frac{1-0.804}{2-0.8420-0.804}=$ 0.55367 for state one and $\frac{1-0.842}{2-0.8420-0.804}=0.44633$ for state two. So we can conclude that for this sample the probability that conditional correlation between series is bigger for state one than state two but not much and it is more probable that the spot and future exchange rate have a higher correlation close to 0.8 as in figure 11. 

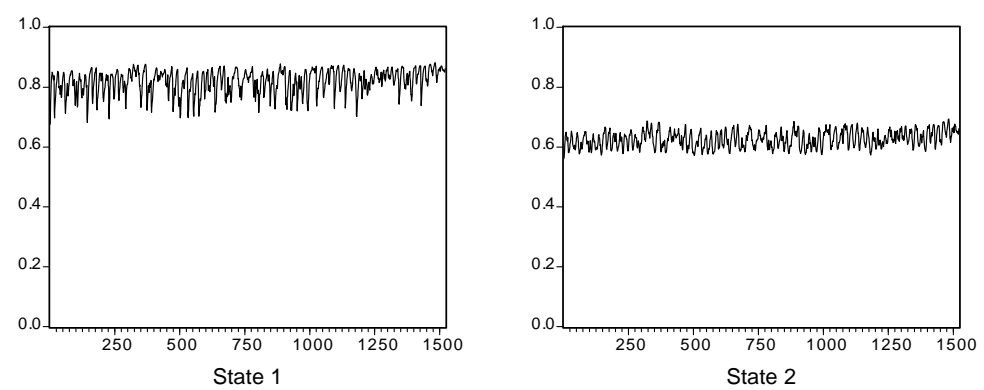

Figure 11: Correlation

Table 10 - Transition Probabilities

\begin{tabular}{l||ll} 
& State One & State Two \\
\hline \hline State One & 0.8420 & 0.158 \\
State Two & 0.196 & 0.804
\end{tabular}

In figure 7 it is observed the filtered probabilities for each state. Their indicate that the probability of been in state one is almost the same of been in state two for each $t$ in average, this behaviour is expected because the ergodic probabilities obtained by model.
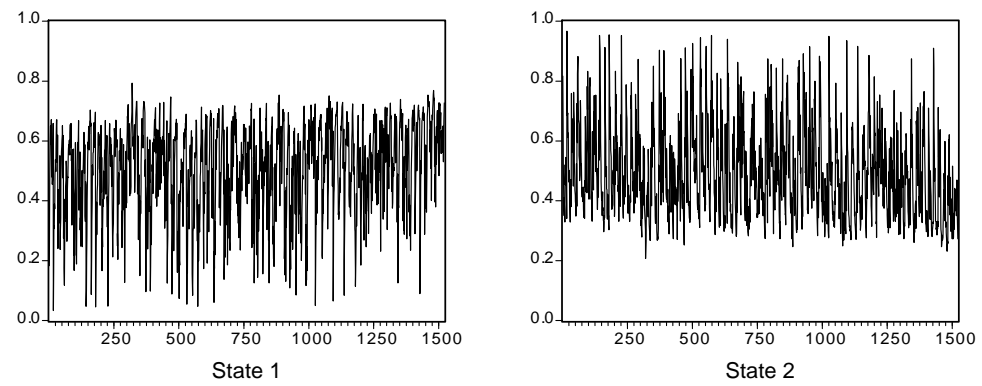

Figure 12: Filtered Probabilities

I plote the optimal hedge ratio estimated in each state in figure 13. Both series are very similar. and they float almost around the same level, differently of the optimal hedge ratios results obtained by Ibovespa Index and reported in figure 8 .

In figure 14 are ploted the expected optimal hedge ratio for each $t$. I can infer that the behavior of graph is very similar compared to figure 13 .

\subsubsection{Variance Reduction}

Table 11 present the results of model's evaluation using the variance reduction criterion to exchange rate. I can infer that using some kind of strategy, then the agents can reduce the variance of his portfolio as the results obtained by Ibovespa index and that the best strategy in-the-sample is given by the switching regime model. A curios fact is that the variance reduction obtained by vector error correction model $(8.82 \%)$ is very small when compared 

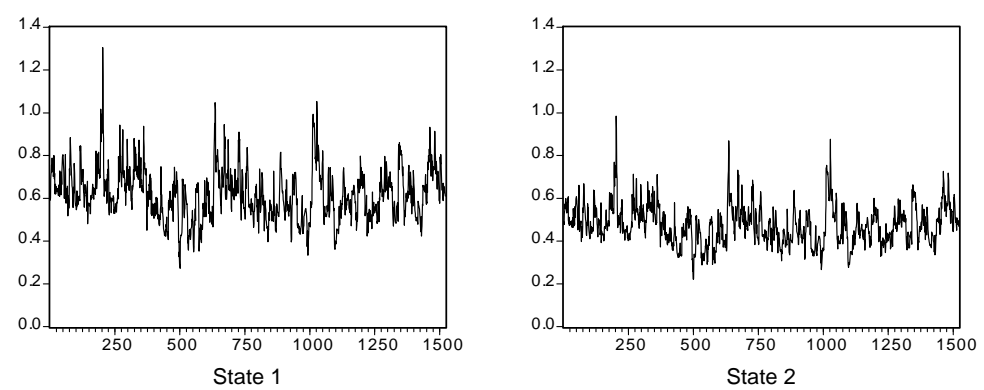

Figure 13: Optimal Hedge Ratio

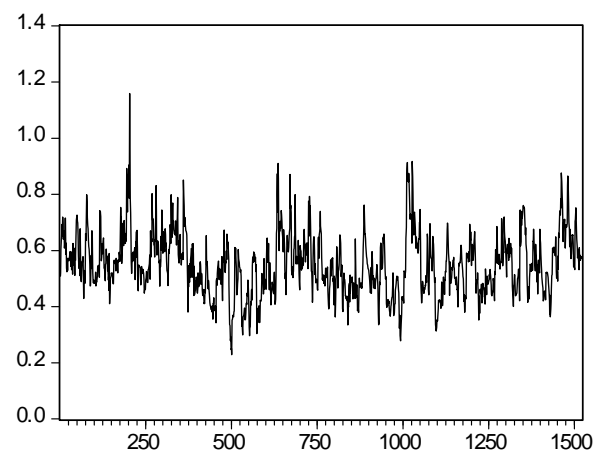

Figure 14: Expected Optimal Hedge Ratio

with variance reduction obtained by ordinary least squares (38.15\%) and switching regime model $(39.73 \%)$ and a naive strategy is a better choice to an optimal hedge ratio than vector error correction term.

\begin{tabular}{|c|c|c|}
\hline \multicolumn{3}{|c|}{ Table 11 - Variance Reduction } \\
\hline & Variance & Variance \\
\hline Unhedge & 0.0000904814249 & \\
\hline Naive & 0.0000817149847 & $9.69 \%$ \\
\hline OLS & 0.0000559637992 & $38.15 \%$ \\
\hline VECM & 0.0000824974200 & $8.82 \%$ \\
\hline MSDCC & 0.0000545306447 & $39.73 \%$ \\
\hline
\end{tabular}

\subsubsection{Utility}

In table 12 are present the values of utility. For all values of coefficient risk aversion the switching regime model is the better choice for exchange rate data. The same result obtained by index data. The vector error correction model is a worse choice when compared with a naive strategy, the same result found out in table 9 for Ibovespa Index. 


\begin{tabular}{ccccc}
\hline \multicolumn{5}{c}{ Table 12 } \\
\hline \multicolumn{5}{c}{ Utility } \\
\hline Risk Aversion & $\mathbf{1}$ & $\mathbf{2}$ & $\mathbf{3}$ & $\mathbf{4}$ \\
\hline \hline Unhedge & -0.000090 & -0.000181 & -0.000271 & -0.000362 \\
Naive & -0.000082 & -0.000163 & -0.000245 & -0.000327 \\
OLS & -0.000056 & -0.000112 & -0.000168 & -0.000224 \\
VECM & -0.000082 & -0.000165 & -0.000247 & -0.000330 \\
MSDCC & -0.000055 & -0.000109 & -0.000164 & -0.000218 \\
\hline
\end{tabular}

\section{Comments and Conclusions}

The results achieved in this dissertation need some further explanation and comments.

For both series some estimated parameters of the conditional correlation equation are zero or not significant but the unconditional correlation and the transition probabilities are significant. So this econometric model says that the probabilities and the unconditional correlation are more important to determine the correlation in each point of time and that there is a switching regime in the correlation data. The fact that the equation parameters are not significant can be a little strange but it is supported by the high correlation behavior that can be assumed from the log level graphs.

The future and spot prices are very narrowly related, so the correlation or covariance between them is high during all the time and sometimes it can change to a lower level. Then for the estimated structure, unconditional correlation and probabilities are important. The correlation is always fluctuating around these two levels of the estimated unconditional correlation.

The filtered probabilities indicate that the correlation between the series does not stay in each state for a long time, as we can see in the pictures of the filtered probabilities. These results, perhaps, can not have an economic interpretation but Lee, Yoder, Mittelhammer and McCluskey (2006) found very similar filtered probabilities to those I found in my work and Lee and Yoder (2007) presented, similarly to my work, not only the filtered probabilities but also some parameter that are not significant and some equal zero.

Concluding, in this work I estimated the optimal hedge ratio using a bivariate markov switching regime dynamic conditional correlation that incorporate a leverage effect in univariate variance and an error correction term. The model was applied in two different data series. The results from the variance reduction and utility indicate that this model is a better choice when compared to ordinary least squares and vector error correction model. An extension of this dissertation is to estimate a model with a markov switching structure for univariate variances and apply the White test to determine the statistic significance between models.

\section{Bibliography}

ALIZADEH, A. \& NOMIKOS, K. A Markov Regime Switching Approach for Hedge Stock Indices, The Journal of Future Markets, vol.24, p.p. 649-674, 2004. 
ANDERSON, R. W. \& DANTHINE, J. The Time Pattern of Hedge and the Volatility of Futures Prices, Review of Economic Studies, p.p. 249-266, 1983.

BAILLIE, R. T. \& MYERS, R. J. Bivariate GARCH Estimation of the Optimal Commodity Futures Hedge, Journal of Applied Econometrics, vol. 6 p.p. 109-124, 1991.

BAUWENS, L., LAURENT, S. \& ROMBOUTS, J. V. K. Multivariate GARCH Models: A survey, Journal of Applied Econometrics, vol. 21, p.p. 79-109, 2006.

BENNINGA, S. , ELDOR, R. \& ZILCHA, I. The optimal hedge ratio in unbiased futures markets. Journal of futures markets, vol. 4, p.p. 155-159, 1984.

BERA, A. K., GARCIA, P., \& ROH, J. S., Estimation of Time-Varying Hedge Ratios for Corn and Soybean: BGARCH and Random Coefficient Approaches, The Indian Journal of Statistics, vol. 59, p.p. 346-368, 1997.

BILLIO, M. \& CAPORIN, M. Multivariate Markov Switching Dynamic Conditional Correlation GARCH Representations for Contagion Analysis, Statistical Methods \& Applications, vol. 14, p.p. 145-161,2005.

BROOKS, C., HENRY, O. T. \& PERSAND, G. The Effect of Asymmetries on Optimal Hedge Ratios. Journal of Business, vol. 75, p.p 333-352, 2002.

BYSTRÖM, H. N. E., The Hedge Performance of Electricity Futures on the Nordic Power Exchange. Applied Economics, vol. 35, p.p.1-11,2003

CECCHETTI, S. G., CUMBY R. E. \& FIGLEWSKI, S. Estimation of Optimal Futures Hedge. Review of Economics and Statistics, vol. 70, p.p 623-630, 1988.

COTTER, J. \& HANLY, J. Reevaluating Hedge Performance. The Journal of Futures Markets, vol. 26, p.p. 677-602, 2006.

CHOW, Y.F., Regime Switching and Cointegration Tests of the Efficiency of Futures Markets. The Journal of Futures Markets, vol. 18, p.p. 871-901, 1998.

EDERINGTON, L. H. The hedge performance of the new futures markets. Journal of Finance, vol. 34, p.p. 157-170, 1979.

ENGLE, R. F., Dynamic Conditional Correlation - A Simple Class of Multivariate GARCH Models. Journal of Business and Economic Statistics, vol. 20, p.p. 339-350, 2002.

ENGLE, R. F. \& GRANGER, C. W. J. Co-integration and Error Correction representation, estimation and testing. Econometrica, vol. 55, p.p. 251-276, 1987.

FAMA, E. F. and FRENCH, K. , Commodity Futures Prices: Some Evidence on Forecast Power, Premiums and the Theory of Storage, The Journal of Business, vol. 60, p.p. 55 - 73.

FIGLEWSKI, S. Hedge Performance and Basis Risk in Stock Index Futures. Journal of Finance, vol. 60, p.p. 55-73, 1984.

FONG, W. M. \& SEE, K. H. A Markov Switching Model of the Conditional Volatility of crude oil prices. Energy Economics, vol. 35, p.p. 71-96.

GAGNON, l. \& LYPNY, G. Hedge short-term interest risk under time-varying distributions. Journal of Future Markets, vol. 15, p.p. 767-783, 1995.

GLOSTEn, L., JAGAnnAThan, R., RUnKLE, D., "On the Relation Between Expected Value and the Volatility of the Nominal Excess Returns on Stocks". Journal of Finance, vol. 48, p.p. 1779-1801, 1993.

GAGNON, L., LYPNY, G. J., and MCCURDY, T. H. Hedge Foreign Currency Portfolios, Journal of Empirical Finance, vol. 5, p.p.197-220, 1998.

HEANEY, J. \& POITRAS, G. Estimation of the Optimal Hedge Ratio, Expected Utility, and Ordinary Least Squares Regression. The Journal of Futures Markets, vol. 11, p.p. 603-612, 1991. 
HILL, J. \& SCHNEEWEIS, T. A note on the hedge effectiveness of foreign currency futures. Journal of Futures Markets, vol. 1, p.p 659-664, 1981.

JOHNSON, L. The Theory of Hedge and Speculation in Commodity Futures. Review of Economic Studies, vol. 27 p.p. 139-151, 1987.

KAVUSSANOS, M. \& NOMIKOS, N. Hedge in the freight futures markets. Journal of Derivatives, vol. 8, p.p. 41-58, 2000.

KIM, C-J. Dynamic linear models with Markov-switching. Journal of Econometrics, vol. 60, p.p. 1-22, 1994.

KRONER, K. \& SULTAN, J. Time-varying Distributions and Dynamic Hedge with Foreign Currency Futures. Journal of Financial and Quantitative Analysis, vol. 28, p.p. 535-551, 1993.

KUWORNU, J. K. M.; KUIPER, W. E.; PENNINGS, J. M. E. \& MEULENBERG M. T. G. Time-varying Hedge Ratios: A Principal-agent Approach. Journal of Agricultural Economics, vol. 56, p.p. 417-432, 2005.

LAMOUREUX, C. G., \& LASTRAPES, W. D. Persistence in Variance, Structural Change, and the GARCH Model. Journal of Business \& Economic Statistics, vol. 8, p.p 255-234, 1990.

LEE, H. T. \& YODER, J. A Bivariate Markov Regime Switching Garch Approach to Estimate Time Varying Minimum Variance Hedge Ratios. Applied Economics, 2007.

LEE,H. T., YODER, J., MITTELHAMMER, R. C. \& MCCLUSKEY J. J. A random coefficient autoregressive Markov regime switching model for dynamics futures hedging The Journal of Futures Markets. vol. 26, p.p. 103, 2006.

LEE, H. T. \& Yoder, J. Optimal hedging with a regime-switching time-varying correlation GARCH model. The Journal of Futures Markets, vol. 27, p.p. 495, 2007.

LI, W K , LING, S. \& MCALEER, M., Recent Theoretical Results of Time Series Models with GARCH Errors, Journal of Economic Survey, vol. 16,p.p. 245-69, 2002.

LIEN, D. The Effect of the Cointegration Relationship on Futures Hedge: A Note. Journal of Futures Markets, vol. 16, p.p. 773-780, 1996.

LIEN, D. Estimation Bias of Futures Hedge Performance: A Note. Journal of Futures Markets, vol. 26, p.p. 835-841, 2006.

LIEN, D. \& LUO, X. Estimating Multiperiod Hedge Ratios in Cointegrated Markets. The Journal of Futures Markets, vol. 13, p.p. 908-920, 1993.

LIEN, D. \& TSE, Y. K., Fractional Cointegration and Futures Hedge, Journal of Futures Markets, vol. 19, p.p. 457-474, 1999.

LIEN, D. \& TSE, Y. K., Some Recent Developments in Futures Hedge, Journal of Economic Surveys, vol. 16, p.p. 357-396, 2002.

MARTINEZ, S. W. \& ZERING, K. D. Optimal Dynamic Hedge Decisions for Grain Producers. American Agricultural Economics Association, p.p. 879-888, 1992.

MYERS, R. J. Estimating Time-Varying Optimal Hedge Ratios on Futures Markets, Journal of Futures Markets, vol. 11, p.p. 39-53, 1991.

MYERS, R. J. \& HANSON, S. D. Optimal Dynamic Hedge in Unbiased Futures Markets, American Agricultural Economics Association,vol. 78, p.p. 13-20, 1996.

PARK, T. H. \& SWITZER, L. N. Bivariate GARCH Estimation of the Optimal Hedge Ratios for Stock Index Futures: A Note. The Journal of Futures Markets, vol. 15, p.p. 61-67, 1995.

PELLETIER, D. Regime Switching for Dynamic Correlations. Journal of Econometrics, vol. 131, p.p 445-473, 2006.

RYDEN T., TERASVIRTA, T. \& ASBRINK, S. Stylized Facts of Daily Return Series and the Hidden Markov Model. Journal of Applied Econometrics, vol. 13, p.p. 217-244. 1998. 
TONG, W. H. S., An Examination of Dynamic Hedge. Journal of International Money and Finance, vol. 15, p.p. 19-35, 1996.

SARNO, L. \& VALENTE, G. Modelling and Forecasting Stock Returns: Exploiting the Futures Market, Regime Shifts and International Spillovers, Journal of Applied Econometrics, vol. 20, p.p. 345-376, 2005.

SARNO, L. \& VALENTE, G. The Cost of Carry Model and Regime Shifts in Stock Index Futures Markets: An Empirical Investigation, The Journal of Future Markets, vol. 20, p.p 603-624, 2000 .

STEIN, J. The Simultaneous Determination of Spot and Futures Prices. American Economic Review, vol. 51, p.p. 1012-1025, 1961.

YANG, W. \& ALLEN, D. E., Multivariate GARCH Hedge Ratios and Hedge Effectiveness in Australian Futures Markets. Accounting and Finance, vol. 45, p.p. 301-321, 2004.

YEH, S. C. \& GANNON, G. L. Comparing Trading Performance of the Constant and Dynamic Hedge Models: A Note. Review of Quantitative Finance and Accounting, vol. 14, p.p. 155-160, 2000 . 